\title{
Delay Study in the Construction Project: An Overview
}

\author{
Shubham Sharma*, Mukesh Pandey**, Sohit Agrawal*** \\ *(M.Tech Student, Department of Civil Engineering, ITM University, Gwalior-474001, India \\ **(Professor \& Head, Department of Civil Engineering, ITM University, Gwalior-474001, India \\ *** (Assistance Professor, Department of Civil Engineering, ITM University, Gwalior-474001, India
}

\begin{abstract}
"Scheduling" is the word when it came in our mind it means the time table and most important thing is that, works should be done in time, but even if we try everything to keep our time table in schedule some of the factors that cause us late by increasing our time, they are called "DELAY FACTOR" and the time increase by them, known as "DELAY". DELAY is the factor which is responsible for every other factors which cause lose of time, money etc. especially the most prominent loss of time and money causes by delay factors is in construction. Today construction growth in the world is increasing day by day. In every part of the world an ongoing construction can be seen, so it is very important to keep every construction on time, but quite often it is not possible because many sub-factors from different main factors cause delay and keep the construction behind the time in comparison of schedule time. The main focus of this paper is to determine the current and most responsible Delay factors by methods of MCDM and by arranging and listing them, with the recommendation to minimizing them.
\end{abstract}

Keywords - construction project, Delay, factors, MCDM methods.

\section{INTRODUCTION}

In every part of the world construction has a rapid growth daily. Larger company takes a larger construction and by finishing those on time play a vital role in the economy of the world. When a construction is need to be start a proper schedule is made by the company management or by the contractor to keep the project on time, but even try all your efforts some of the factors or reason which causes delay, known as delay factors. Delay factors can be related to the many categories which include sub factors or sub-sub factors. These categories can be of owner, labor, material, contractor, consultant and many other factors. If we look at the past and present (on-going) construction projects situation in India, we can see that out of the $100 \%$ project almost $90 \%$ of the project is completed late or running behind schedule due to one or many of the delay factors, only few projects are complete on time. Due to delay in construction work there are many problem occurs or introduce like over running time, over running cost etc.

So a study is been made to know that which factor in which category is the most prominent and more responsible for causing the delay in the construction project and also effect the other factor and create disturbance in the economic and GDP growth rate of the country.

\section{OBJECT AND MOTIVE}

The critical review in this paper includes the definition of delay, factor responsible for delay and how they affect other factors. This paper mainly
Focus on the factor which is more responsible for delay. This study includes the important method of MCDM (Multi-criteria decision making or analysis). MCDM is the operative research for direct or straight forward to evaluate multiple options in decision making. MCDM method will help in ranking the factors and critical sub-factors which are mainly responsible for delays in the construction project, by giving ranking to them will give us an idea that which factor is mostly responsible and what are the recommendation can be take to minimize them.

\section{LITERATURE REVIEW}

During this case study different literatures have been read out, here are some of them which describe the categories and some of the factors which are mostly responsible for the construction delays and also tell us about how to minimize their effect. They are-

Perara, N. and Sutrisna, M. The focus of this paper is on to the equal priorities should be given to everyone to minimize or stops delay claims in the construction industry but however this responsibility is been fettered by both the contractor and the client also. The main goal of this research is to find that which one of the factors is mainly abstractive, and that is one of the factors is to apportioning their liabilities. An AHP method is being used as the appropriate decision making tool to form a model and to identifies the obstructive factors the selection of the AHP in the research, is how its ability to analysis both the qualitative and quantitative data by assigning various numerical values. 
Mohammad Mufazzal Hossen, Sunkoo Kang Jonghyun Kim, This study carries the construction schedule delay in international project. A Questionnaire was conducted on the AHP analysis hierarchy process. The case study conclude 4 main factor is $1^{\text {st }}$ level and 12 sub and 32 sub-sub factors in $2^{\text {nd }}$ and $3^{\text {rd }}$ level in that determines the top most 5 sub-sub factors and how to minimize the effect of that. With the steps taking out in this study the researches of this project is rarely face and delay risk. An AHP method is used to deal with both qualitative and quantitative the main.

Ghada Taha', Mohammed Badawy², Omar ELNawawy $^{3}$, The aim is to find the main construction delays in projects. The ten groups of 63 factors include in this. Survey is conducted after making a questionnaire. Top most important factor comes out in this study. These are the delay in advance installments by owner, poor site supervision by the contractor, absence of qualified labor, trouble in financing ventures by the contractor and last however not the slightest insufficient arranging and planning of Ventures by the contractor. A model is developing to fine the importance of each factor and the user will give a proper attention to them to reduce project delays.

Shabbab Al Hammadi, M. Sadique Nawab, as one thing which pays attention to all, is that construction play a major role in economy of country especially in the developed country. The time or duration takes place by construction shows the success of the project. This paper states that a survey was conducted by making questionnaire between project managers. Consultant and engineers is to get their response. The owner role, financing problem, contractor related, and material related, Design documents have been mentioned as the main delay problem. This review also suggested that the time and cost over-run delay survey also done in past and the 7 delay factors, Which have strongly comes out, they are slowness, lack of constraint, incompetence, design, market, estimate financially, govt. and worker. Current research and research done in post compares so these 7 delay factor come our very strongly.

Prof: Siddesh K Pai and Mr. J. Raj Bharath, as the difficulty and complexity of the present construction project, delays become one of the factors which create many problems like cost overrun and many others. Many methods have been used by the research to find out the main delay factor. A 300 crores project become 1600 crores by the delay factor and it was none of them Mumbai (BandraWarli sea link).
Delays create that much problem. So a survey was conducted with in different construction companies in India to find out the factor course main delay. 73 causes of delay were found in that survey. There are 20 contractors, 1 consultant and 1 owner was included in that survey. To reduce the delay the initial step to find the root of delay and the step to be taken to reduce or stop that delay.

\section{REVIEW STATES SOME OF THE MAIN DELAY CATEGORIES WHICH INCLUDE THEIR CO-FACTOR OR SUB-FACTORS THEY ARE:-}

\subsection{Owner Related}

Owner or client is the one who can be mainly responsible because almost $50-60 \%$ of decision on work should be made by him. The factors which can cause delay are slow decision, delay in payment, suspension of work, interference. These factors can create problem. They should be control in order to run the work smoothly.

\subsection{Consultant Related}

The person appointed for advice in the decision making also create problem some time by some of the factors like his poor experience. Delay improving design, poor advice, delay in inspection the mistake done by him lead a very healthy delay in construction.

\subsection{Contractor related}

The main focus is on construction schedule which should be kept on time by everyone specially the responsibility of the contractor. Contractor is one due to its poor quality of decision making like difficulty in allocation of work, the rework due to errors, an improper planning/scheduling may extend the project period. His thinking of understanding the project as financially should also good otherwise a very high dispute can happen between the client and contractor.

\subsection{Labor Related}

Labor has one of the main responsibilities to keep construction on schedule. To handle the labor is not an easy task. With the problem create by labor can easily delay our construction, also increase your cost of the project, some of the factor which have come out in review is like their lack of qualified labor, poor experience of work, their health, and labor productivity. One of the main factor are their conflicts, it can be between labors or with the contractor. So this factor should be take care at starting of the project to run the work efficiently. 


\subsection{Equipment related}

Equipment has brought to make the work of labor easy or more efficiently, but the thing which made the work more easily sometimes it makes the work more difficult also. EQUIPMENT is one of them. Their sudden breakdown can cause more damage, low level, productivity and their poor operating skill may easily apply a sudden break on construction work. So a more quality, more efficient, more durable machine should take during construction.

\subsection{Material related}

Construction work is completely depending on the availability of construction material. The rate of construction work of any project is directly proportional to the material required \& availability of material. If material is available in better quantity then rate of construction is goes in smooth way while shortage of material cause delays in construction work. Their delay in delivering or their shortage late procurement causes the construction delay. Material for construction is like breathing for human body.

\subsection{External or Miscellaneous Related}

The factor shows in six categories, they are related to the construction in many ways, but some of the other factor is also there may be called external which in other way causes the construction delays. Some of them which come out from literature review are climatic, sub-surface condition, unavailability of utilities and many more. A proper planning should be there to face this external factor during the time of construction to stop the delays.

\section{CONCLUSION}

The review undertaken in this paper covers the definition of delay. An attempt has been made to find the factors responsible for delay. In this rapid increasing construction sector, looking towards the flexibility of the project the proper management of these factors can help to minimize their effect on the industry. Every time it is difficult to avoid the construction delays but an attempt can be made to keep construction on schedule because finishing the big budget project on time play a vital role in economy of country

\section{REFERENCES.}

[1] Ghada Taha, Mohamed Badawy, and Omar EL-Nawawy, A model for evaluation of delays in construction project, International General of Innovative Research in Science Engineering and Technology, 5(3), 2016, 3021-3028.

[2] Prof. Siddesh K Pai, Mr. J. Raj Bharath, Analysis of Critical causes of Delay in
Indian Infrastructure Projects, International Journal of Innovative Research and Development(IJIRD), 2(3), 2013, 251-263.

[3] Shabbab AI Hammadi, M. Sdique Nawab, Study of Delay Factor in Construction Project, International Advance Research Journal in Science, Engineering and Technology, 3(4), 2016, 87-93.

[4] Perera N. and Sutrisha M., The use of AHP in the Analysis of Delay Claims in Construction Project in UAE, The Built \& Human Environment Review, 3(1), 2010, 47-48

[5] MUHAMMED MUFAZZAL HOSSEN, SUNKOO KANG and JONGHYUN KIM, Construction Schedule Delay Risk Assessment by using Combined AHP and RII Methodology for International NPP Project, ELSEVIER, 2015, 47(3), 362-369.

[6] Anil Upadhyay , Himanshu Agrawal, Hanish Jain, A study contractor related delay factors in construction, International Research Journal of Engineering \& Technology, 3(8), 2016, 1162-1164.

[7] Dinesh Kumar R, Causes and effects of delay in Indian construction Project, International Research Journal of Engineering \& Technology, 3(4), 2016, 1831-1837.

[8] Nashwan AI-Emad, Sasitharan Nagapan, Identification of delay factors in Mecca's construction expert prespective", International journal of sustainable construction engineering and technology, 6(2), 2015, 16-25. 